\title{
Delivery Site Preferences and Associated Factors among Married Women of Child Bearing Age in Bench Maji Zone, Ethiopia
}

\author{
Fira Abamecha Ababulgu ${ }^{1}$, Tariku Tesfaye Bekuma ${ }^{1}$
}

\section{ABSTRACT}

BACKGROUND: Efforts to reduce maternal mortality and morbidity must address societal and cultural factors that affect women's health and their access to services. There was no research conducted previously on delivery site preferences and associated factors among married women of child bearing age in the study area. The aim of this study was to assess the delivery site preferences and associated factors among women of child bearing age in Bench Maji Zone, Southwest Ethiopia.

METHODS: A community based cross sectional quantitative study design supplemented by qualitative data was conducted from April 20 to May 20, 2013. Simple random sampling to select kebeles and systematic random sampling to contact eligible woman were used. Data was collected using structured questionnaire. Data was analyzed by using SPSS version 16. Logistic regressions analysis was employed to identify potential predictor variables. Odds ratio with $95 \%$ confidence interval was used to assess the association of variables. P-value less than $5 \%$ was used to declare significant association.

RESULTS: Three hundred five (61.9\%) of the mothers gave birth at home. Three Hundred ninety six (78.7\%) of them had Ante natal care. The preference of facility delivery was 412(88.3\%). Age of women, mothers' educational level, and place of delivery of the last baby, perception of mothers about pregnancy and health care workers significantly affected delivery site preference.

CONCLUSION: Most of the women attended Ante natal care. However, only some had actually delivered at health facilities to their last pregnancy. Community members should get health education to reduce misconceptions on delivering in health facility.

KEYWORDS: Delivery preference, Institutional delivery, Antenatal care

DOI: http://dx.doi.org/10.4314/ejhs.v25i4.9

\section{INTRODUCTION}

Reproductive health care is a highly focused issue in the development of a country. Delivery service to pregnant women is the most important component of reproductive health care, to handle high risk deliveries. In spite of the national and global efforts for reducing maternal morbidity and mortality, there is no significant reduction in maternal morbidity and mortality in developing countries $(1,2)$. In 2013, about 800 women died daily due to complications of pregnancy and child birth. Almost all of these deaths occurred in lowresource settings, and most could have been prevented. (3). In Ethiopia, maternal mortality and morbidity levels are among the highest in the world. Maternal mortality ratio is currently 676 per 100,000 live births $(3,4)$. The majority of maternal deaths is due to obstetric complications that could have been prevented with adequate medical care by skilled attendants during and after delivery $(1,5)$. Globally, one third of births take place at home without the assistance of skilled attendants (5). In Africa, less than $50 \%$ of births are attended by skilled health workers $(2,6,7)$.

According to EDHS 2011, the proportion of institutional delivery in Ethiopia in general and in southern region in particular was $10 \%$ and $6.2 \%$ respectively (8). Studies conducted in different parts of Ethiopia showed that the institutional

\footnotetext{
${ }^{1}$ Department of Nursing, Mizan Tepi University, Ethiopia

Corresponding Author: Fira Ababulgu, Email: firamecha@gmail.com
} 
delivery was $18.2 \%$, and $12.1 \%$ respectively (9, 10). Studies conducted in Zambia and in Malawi in 2011 showed that institutional delivery was $42.5 \%$ and $58 \%$ respectively $(11,12)$. ANC helps pregnant women to make birth plan including transport in case of complications. According to EDHS 2011, the prevalence of ANC in Ethiopia and SNNPR were $34 \%$ and $27.3 \%$ respectively. In the previous studies, utilization of delivery service was found higher in the younger age group (15-24 years) as compared to lower utilization of the services by mothers in the age groups of 25-34 years and above $(8,10,13)$. The finding of studies carried out in Ethiopian $(8,9$, 10) and those done in Bangladesh and Zambia showed that mothers with higher educational status were more likely to utilize delivery care service $(14,11,13)$. Antenatal care service is the most important factor influencing delivery service utilization as in most studies $(15,16,17,10)$. However, other studies $(18,9)$ showed that it has no influence on preference of institutional delivery. On the other hand, studies conducte in Kenya which identified that mothers tend to be more likely to deliver the last baby in the same place they delivered during the first delivery. This shows that the first experience a mother had at the chosen place of delivery and with the chosen birth attendant was very important $(19,20)$. The finding from studies conducted in Nepal and Bangladesh reveals that moral support in making wait and giving priority on the basis of caste, ethnicity, language and religion all discourage the use of institutional delivery. Studies $(21,22)$ showed that mothers also worry about privacy and confidentiality According to EDHS 2011 and previous studies, mothers who believed that sudden onset of short lasting labor that may accidentally occur combined with absence of transport facility or lack of money for transportation cost are less likely to use institutional delivery $(11,14,22)$.

Lack of financial resources among rural mothers, which leaves them to the decision of their husbands or relatives, also affects facility delivery $(23,24,25)$. Efforts to reduce maternal mortality and morbidity must thus address societal and cultural factors that affect women's health and their access to services (26).

In Bench Maji Zone, inadequate access to integrated, affordable and quality reproductive health (RH) services, unplanned pregnancies, little participation of men in $\mathrm{RH}$ issues and unsafe motherhood have been reported to influence provision of reproductive health services despite the efforts from government. There was no research conducted previously in this particular area on the topic under consideration. Therefore, this study was aimed to determe delivery site preferences and practices as well as factors influencing the choices of child bearing mothers in the zone.

\section{MATERIALS AND METHODS}

Study area and design: A community based cross sectional quantitative study design supplemented by qualitative data was used to assess delivery site preferences among married women of reproductive age group in Bench Maji Zone from April 20 to May 20, 2013. Bench Maji Zone is located in Southern Nation Nationality Regional State (SNNP), Southwest Ethiopia, around $565 \mathrm{~km}$ away from the capital city, Addis Ababa, with its center, Mizan Teferi Town. In this zone, there are one town administration and 10 rural districts. The zone's total population is 781,006 out of which women of childbearing age are 181, 974. In addition, there are one general hospital, 35 health centers, 182 Health posts, one university and one Health sciences college.

Study participants: All currently married women between 15-49 years of age who were living in selected kebeles of the zone (kebele is the smallest administrative unit of Ethiopia consisting of at least 500 families).Mothers who have at least one child birth at the time of the survey were included. While, those who were critically ill, could not talk or listen were excluded.

Sample size and sampling procedure: Sample size was determined using the formula for a single population proportion: Prevalence (p) of institutional delivery among child bearing women which is $18.2 \%$ was used (14) to calculate total sample of 458 . Adding $10 \%$ allowance for nonresponse and refusal to participate, a total of 504 married women were selected.

Among 10 districts and one administrative town in Bench Maji Zone, five districts were randomly selected from which 504 respondents were selected. Then, the sample for each selected district was allocated proportional to the population size. The districts were further 
classified into kebeles and the kebeles were randomly selected. Households in selected kebeles were selected using systematic random sampling technique to contact and interview eligible women. Regarding sampling frame, all of the households in the selected kebeles were enumerated. Closed households during data collection were revisited three times at different times. The next nearest households were included for unsuccessful visits. To supplement quantitative data, in-depth interview was conducted with a total of 20 individuals [health professionals, HEWs, model mothers and religious leaders] judgmentally selected from each of the five districts of the study. The interview was not intensive exploratory as it was simply intended to supplement the quantitative study. The interview guide was developed based on the predetermined specific quantitative research objectives.

Data collection tools and procedure: Both the interviewers and supervisors were given a two days' training before the actual work about the aim of study and data collection techniques by going through the questionnaire question by question. After pre-test had been made, data was collected by interviewing married women by interviewer using a structured questionnaire. The questionnaire incorporated questions addressing socio-demographic variables, preference of delivery site and factors affecting the preferences among married women who delivered at least one child in the study area. It was prepared in English and translated to Amharic, the official language of Ethiopia. Qualitative data was collected using unstructured interview guideline. Each interview was recorded using ape recorder.

Data quality assurance: Data quality was assured by properly designing and pre-testing the questionnaire, training the interviewers and supervisors on data collection procedures and, categorizing and coding of the questionnaire. Questionnaire was checked everyday for completeness by the supervisors and the necessary feedback was offered to data collectors in the next morning before data collection. Qualitative data was directly collected by the principal investigators. Different categories of respondents were recruited to ensure credibility. Transcription and coding was done by two different individuals separately to check cridebility of the findings and interpretations. Also, in addition to triangulating the qualitative findings with the quantitative one, direct quotes of individual respondents were used

Data processing and analysis: Data was entered using EPI INFO version 3.5 statistical packages. It was exported to statistical packages for social scientists (SPSS) software (v 16.0; IBM Corporation, Armonk, NY, USA), where coding, recoding and categorizing were done. Mean, standard deviation and percentage were used as descriptive statistics and summary measures. Using odds ratio (OR) with $95 \%$ limit of confidence interval, the association of dependent and independent variables was assessed and their degree of associations was computed. P-value $<5 \%$ was considered to show significant statistical association.

Qualitative data was first reread and transcribed. Coding and categorization was done to form primary themes based on a predetermined concepts/objectives of the study.

Besides, quotes of participants' expressions that exemplify key concepts were used directly during analysis and then, the concepts were developed into major themes under each discussion guides. Finally, the result was triangulated with that of the quantitative one.

Ethical considerations: Ethical clearance was obtained from the Research Ethics Committee of the College of Health Sciences, Mizan-Tepi University, before data collection. Then, permission letter was obtained from each district administrators, and verbal consent was taken from each eligible woman in each selected kebele. Study participants were informed that the study would not have any risks. In addition, the objective and benefits of the study were explained to them. Items seeking personal information (name, phone number, etc) were not included in the questionnaire to ensure privacy and confidentiality.

\section{RESULTS}

Socio-demographic characteristics: The overall response rate was 503(98\%). Of the total respondents, 327(65\%) were illiterate. About $259(51.5 \%)$ were from Bench ethnic group, $449(89.3 \%)$ were housewives, while $277(55.10 \%)$ were Protestant, and 148(29.4\%) were in the age group of $25-29$ years with a mean age of $29.69 \pm 6.97$ years. (Table1). 
Table 1: Socio demographic characteristics of respondents in Bench Maji Zone, Ethiopia, 2013

\begin{tabular}{|c|c|c|}
\hline Respondents characteristics & Number of women & Percent \\
\hline \multicolumn{3}{|l|}{ Age } \\
\hline$<24$ & 114 & 22.7 \\
\hline $25-29$ & 148 & 29.4 \\
\hline $30-34$ & 102 & 20.3 \\
\hline $35-39$ & 78 & 15.5 \\
\hline$>40$ & 61 & 12.10 \\
\hline \multicolumn{3}{|l|}{ Ethnicity } \\
\hline Bench & 259 & 51.5 \\
\hline Amhara & 123 & 24.5 \\
\hline Menit & 59 & 11.7 \\
\hline Kaficho & 42 & 8.3 \\
\hline Others (Oromo, Tigre, Guraghe) & 20 & 4.0 \\
\hline \multicolumn{3}{|l|}{ Religion } \\
\hline Protestant & 277 & 55.10 \\
\hline Orthodox & 149 & 29.6 \\
\hline Muslim & 48 & 9.5 \\
\hline Others (Catholic, Johva Witness) & 27 & 5.4 \\
\hline \multicolumn{3}{|l|}{ Mothers education } \\
\hline Cannot read and write & 327 & 65 \\
\hline primary education & 162 & 32.2 \\
\hline Secondary education and above & 14 & 2.8 \\
\hline \multicolumn{3}{|l|}{ Residence } \\
\hline Rural & 405 & 80.5 \\
\hline Urban & 98 & 19.5 \\
\hline \multicolumn{3}{|l|}{ Mothers occupation } \\
\hline Housewife & 449 & 89.3 \\
\hline Employed & 20 & 4 \\
\hline Merchant & 14 & 2.8 \\
\hline Daily laborer & 11 & 2.2 \\
\hline Others (servant, coffee seller) & 8 & 1.6 \\
\hline Total & 503 & 100 \\
\hline
\end{tabular}

$\checkmark \quad$ Cannot be added up to 503 because of missing values

$\checkmark$ SD: standard deviation

Health facility delivery, ante natal care (ANC) and pregnancy related complications: Out of the 495 respondents, $305(61.9 \%)$ gave birth to their last child at home while the rest, 190(38.1\%), gave birth at health facility by skilled birth attendants (doctors, nurses midwives and trained HEWs), While unskileed birth attendants (neighbors, relatives and traditional birth attendants (TBAs) attended the rest. On average, mothers in the study area had $3.9 \pm 2.37$ total numbers of children. The average age of mothers was $29.68 \pm 7.00$ years. Three hundred ninety six $(78.7 \%)$ of them had ANC services. With regard to obstetric complications for the recent pregnancy, 244 $(52.8 \%)$ of the respondents report they had faced problems before and during time of labor.

Among the total home deliveries, about 37(12.9\%) of women gave birth alone or in the absence of assistants or relatives (Table 2). 
Table 2: Health Facility delivery and history of pregnancy related health problems of the reproductive age women, Bench Maji Zone, Ethiopia, 2013.

\begin{tabular}{|c|c|c|c|}
\hline Items & & Number of women & Percent \\
\hline \multirow{2}{*}{$\begin{array}{l}\text { Delivery site for the previous } \\
\text { pregnancy }(\mathrm{N}=43)\end{array}$} & Home & 36 & 83.7 \\
\hline & Health facility & 7 & 16.3 \\
\hline \multirow{2}{*}{$\begin{array}{l}\text { Delivery site for the last } \\
\text { pregnancy }(\mathrm{N}=495)\end{array}$} & Home & 305 & 61.9 \\
\hline & Health facility & 190 & 38.1 \\
\hline \multirow{2}{*}{$\begin{array}{l}\text { Future delivery site } \\
\text { preference }(\mathrm{N}=467)\end{array}$} & Home & 55 & 11.7 \\
\hline & Health facility & 412 & 88.3 \\
\hline \multirow[t]{4}{*}{ Complications in the last delivery } & Yes & 244 & 52.8 \\
\hline & No & 218 & 47.2 \\
\hline & prolonged labor & 193 & 48.5 \\
\hline & heavy bleeding & 88 & 22.7 \\
\hline \multirow[t]{4}{*}{ Types of complication } & retained placenta & 34 & 9.4 \\
\hline & abdominal cramp & 44 & 11.8 \\
\hline & loss of consciousness & 10 & 2.2 \\
\hline & Others & 17 & 4.3 \\
\hline \multirow{2}{*}{$\begin{array}{l}\text { ANC attendance for last } \\
\text { pregnancy }\end{array}$} & Yes & 396 & 78.7 \\
\hline & No & 107 & 21.3 \\
\hline \multirow{3}{*}{$\begin{array}{l}\text { Assistant for last pregnancy at } \\
\text { facility }(\mathrm{N}=185)\end{array}$} & Doctor & 20 & 10.4 \\
\hline & Nurse/midwife & 128 & 68 \\
\hline & HEWs & 37 & 21.6 \\
\hline \multirow{6}{*}{$\begin{array}{l}\text { Assistant for last pregnancy at } \\
\text { home }(\mathrm{N}=286)\end{array}$} & TBA & 6 & 2.1 \\
\hline & TTBA & 45 & 15.7 \\
\hline & HEW/CHW & 7 & 2.7 \\
\hline & Friends/relatives & 152 & 53.1 \\
\hline & Others & 39 & 13.6 \\
\hline & No one & 37 & 12.9 \\
\hline \multirow[t]{2}{*}{ Total number of children } & $<=5$ & 398 & 79.4 \\
\hline & $>5$ & 103 & 20.6 \\
\hline
\end{tabular}

Birth preparedness: In the present study, among 473 women interviewed, about 305(64.5\%) and $83(17.5 \%)$ responded that the site of delivery was determined by themselves and by their husbands, respectively. Women were also asked whether they had set aside money for transport in preparation for time of delivery. A significant number, $116(52.5 \%)$ of women, had money saved for transport while 106(47.5\%) did not.

Delivery site preferences and associated factors: Women were interviewed for their choices or preferences to delivery sites provided that all circumstances are favorable. With this regard, $408(87.3 \%)$ preferred a public clinic and $4(0.9 \%)$ private clinic. However, about 53(11.7\%) and $2(0.4 \%)$ preferred home and TBA delivery. However, about 188(38.1\%) had actually delivered their last babies at health facilities. It was clear that some of the mothers failed to get a skilled attendant although they had the will. This might be due to the prevailing circumstances, like birth preparedness and economic factors, that prevented them from getting assistance of a skilled health worker. For instance, 106(47.5\%) did not have money for transportation at delivery time.

Multivariate logistic regression analysis was also performed to predict the preference of institutional delivery in the future using variables that were statistically associated during the bivariate analysis. The result showed that mothers whose 
aged greater than 40 were less likely to prefer institutional delivery compared to mothers of lower age $(\mathrm{AOR}=0.19$ and $95 \% \mathrm{CI}=[0.08-0.46]$. Mothers who had primary education were more likely to utilize institutional delivery than those who cannot read and write $(\mathrm{AOR}=2.03$ and $95 \% \mathrm{CI}=[1.09,3.77]$. Mothers who gave birth to the last child in health facility were less likely to prefer institutional delivery than those who gave birth at home $[\mathrm{AOR}=.24$ and $95 \% \mathrm{CI}=[.11, .52]$. Women who had total number of children greater than five were less likely to prefer facility delivery
$[\mathrm{AOR}=.44$ and $95 \% \mathrm{CI}=[.24, .82]$. Mothers who perceived that labor is unpredictable and it may happen on the way accidentally and who worry or feel shy about the gender of HCWs were less likely to utilize delivery service than their counterparts $(\mathrm{AOR}=.44$ and $95 \% \mathrm{CI}=[.27, .74]$, $(\mathrm{AOR}=.39$ and $95 \% \mathrm{CI}=[.22, .70]$ respectively. Mothers who do not fear or feel shy if HCWs are not among their religion group were more likely to prefer facility delivery than those who worry $(\mathrm{AOR}=2.38$ and $95 \% \mathrm{CI}=[1.09,5.21]$ (Table 3$)$.

Table 3: Independent predictors of Preference of delivery site among married reproductive age women of Bench Maji Zone, 2013

\begin{tabular}{|c|c|c|c|c|}
\hline \multirow[t]{2}{*}{ Variables } & \multicolumn{2}{|c|}{ Preference of delivery site } & \multirow[t]{2}{*}{ Crude OR(95\% C.I) } & \multirow[t]{2}{*}{ Adjusted OR (95\% C.I) } \\
\hline & Yes & No & & \\
\hline \multicolumn{5}{|l|}{ Age category } \\
\hline$<24$ & 95 & 19 & Ref. & Ref. \\
\hline $25-29$ & 120 & 28 & $.86[.45,1.63]$ & $.90[.43,1.88]$ \\
\hline $30-34$ & 85 & 17 & $1.0[.49,2.05]$ & $1.17[.51,2.70]$ \\
\hline $35-39$ & 52 & 26 & $.40[.20, .79]^{*}$ & $.46[.20,1.04]$ \\
\hline$>40$ & 27 & 31 & $.17[.09, .36]^{*}$ & $.19[.08, .46]^{*}$ \\
\hline \multicolumn{5}{|l|}{ Mothers education } \\
\hline Illiterate & 228 & 99 & Ref. & Ref. \\
\hline primary education & 154 & 22 & $3.04[1.83,5.04]^{*}$ & $2.03[1.09,3.77]^{*}$ \\
\hline \multicolumn{5}{|c|}{ Place of last delivery } \\
\hline Home & 176 & 12 & Ref. & Ref. \\
\hline Health facilities & 206 & 109 & $.13[.07 .24]^{*}$ & $.24[.11, .52]^{*}$ \\
\hline \multicolumn{5}{|l|}{ Number of children } \\
\hline$<=5$ & 331 & 69 & Ref. & Ref. \\
\hline$>5$ & 51 & 52 & $.20[.13, .33]^{*}$ & $.44[.24, .82]^{*}$ \\
\hline \multicolumn{5}{|c|}{ Home delivery is safe } \\
\hline Disagree & 239 & 48 & Ref. & Ref. \\
\hline Agree & 143 & 73 & $.39[.26, .60]^{*}$ & $.71[.41,1.22]$ \\
\hline \multicolumn{5}{|c|}{$\begin{array}{l}\text { Labor may occur on the } \\
\text { way accidentally }\end{array}$} \\
\hline Disagree & 245 & 44 & Ref. & Ref. \\
\hline Agree & 137 & 77 & $.32[.21, .49]^{*}$ & $.44[.27, .74]^{*}$ \\
\hline \multicolumn{5}{|c|}{$\begin{array}{l}\text { Fear of sex of HCWs } \\
\text { (male) }\end{array}$} \\
\hline Disagree & 313 & 76 & Ref. & Ref. \\
\hline Agree & 69 & 45 & $.37[.24, .57]^{*}$ & $.39[.22, .70]^{*}$ \\
\hline \multicolumn{5}{|c|}{ Fear of religion of HCWs } \\
\hline Disagree & 27 & 25 & Ref. & Ref. \\
\hline Agree & 335 & 96 & $3.42[1.90,6.20]^{*}$ & $2.38[1.09,5.21]^{*}$ \\
\hline
\end{tabular}

\section{DISCUSSION}

The study tried to identify the preference of institutional delivery and associated factors among married reproductive age women in general population in Bench Maji Zone. The results of the study showed that institutional delivery service utilization was $38.1 \%$ in the zone. This is higher than the findings of studies conducted in Oromiya, North West, Ethiopia, and EDHS 2011, which 
were $18.2 \%, 12.1 \%$ and $10 \%$ respectively $(8,9$, 10). This difference might be due to time of the study (the other studies were conducted two years back). The due emphasis given to the development of health extension programs in training the HEWs and the expansion of the health facilities in recent years could also be possible reasons. On the other hand, institutional delivery status in this study area was lower compared to the study conducted in Goba district, Ethiopia, which indicated that $47 \%$ of the mothers delivered in health facilities. This discrepancy may be related to cultural differences among the two communities. The other possible factor may be the difference in source population since this study was conducted at zonal level and the one in Goba at Woreda level [27].

However, the studies conducted in Zambia and Malawi in 2011 showed that institutional delivery was $42.5 \%$ and $58 \%$ respectively $(11,12)$. This could be due to the difference in demographic and socioeconomic status among the countries.

The reasons behind encouraging women to deliver in health facilities is that they can be attended by skilled attendants and get emergency attention in occasions of complications. In this study, about $152(53.1 \%)$ of the mothers who gave birth at home to their last child were assisted by unskilled attendants, friends or relatives, and 37(12.9\%) gave birth. The result of this study goes with the study in Kenya which identified that $51.8 \%$ of the deliveries were attended by unskilled birth attendants (26).

About $78.7 \%$ of the women interviewed had ANC services. The result is higher than the Ethiopian studies, which were $34 \%$ (of which $27.3 \%$ in SNNPR), and $66.8 \%$ respectively $(8,10)$. Similarly, it is comparable to the other study conducted in Ethiopia, which reported the ANC services as $82 \%$ (9). It is clear that ANC helps pregnant women make birth plan including transportation in case of complications. This study revealed that birth preparedness was not as high as ANC because prevalence of ANC was $78.7 \%$ while only $52.5 \%$ of mothers get prepared (put money aside) for institutional delivery. This issue was supported by qualitative findings:

"...In our locality, the proportion of mothers giving birth to health center is about 7\% in 2012 and $13 \%$ in 2013. But this number does not indicate all mothers attending ANC. Only those who face problems/complications come to our clinic". (A head of health center)

$\mathrm{He}$ mentioned the reasons for the discrepancy between ANC and institutional delivery as:

"...mostly labor comes at night, decision of the parents, and absence of pre-labor complications influence them at large. They usually come only after retained placenta has occurred."

This might be attributed to inadequate information about the importance of institutional delivery, economic problems (about $47.5 \%$ of mother in this study did not have money), distance from health facility (about $25.7 \%$ of women lived within the radius $>5 \mathrm{KM}$ ) and other social factors like capability of decidings place of delivery (as about $35.5 \%$ of the mothers said that place of delivery is decided by their husbands and other relatives).

Concerning preferences of delivery site, About $412(88.3 \%)$ chose both public clinic and private facility, and 55(11.7\%) chose home delivery and wanted to be assisted by relatives. This may be due to the relatively high prevalence of ANC in the study area that $396(78.7 \%)$ of the women had at least one ANC attendance although there are some problems which directly affect quality of delivery services. However, about188(38.1\%) had actually delivered at health facilities to their last pregnancy. It was clear that some of the mothers failed to get a skilled attendant although they were willing. This might be due to the prevailing circumstances, like distance from health facility, quality of ANC, birth preparedness, decision making power, that prevented them to get assistance of a skilled health worker.

A 23 years old HEW has more regarding decision making power:

“....you know; pressure from grandparents of both the husbands and wives, locally called 'amach/amat.'affects women. They take laboring mother to clinic only when they recognize the occurrence of complications."

Up on multivariate logistic regression analysis, the factors associated to preferences of delivery sites were identified. Mothers of the higher age (i.e. $>40$ years) were less likely to prefer health facility as compared to the mothers aged less than 24 years. In previous studies, utilization of delivery service was higher in younger age group (15-24 years) compared to lower utilization of the services by mothers within age groups of 25-34 
years and above (13). This finding is also consistent with EDHS and a study done in Northwest Gondar, Ethiopia, which showed that younger mothers were more likely to utilize the service than older ones $(8,10)$. The possible explanations might be that younger women are more likely to be literate than older women and older women believe giving birth at home is not risky as they have previously experienced birth there.

Mothers who have primary education have two times more likely to prefer institutional delivery than those who cannot read and write. This finding is similar with other studies conducted in Ethiopia $(8,9,10,13)$ and studies done in Bangladesh and Zambia which showed mothers with higher educational status were more likely to utilize delivery care services $(14,11)$.

In this study, ANC, which is expected to be the most important factor influencing delivery service utilization as in most studies $(15,16,17,10)$, was not significantly associated with institutional delivery. The finding is consistence with other studies conducted in Ethiopia $(18,9)$. In the present study, of the mothers who had ANC follow up for the last pregnancy, it was only $38 \%$ that had institutional delivery. This might be attributed to the quality of ANC programs and communication between provider and mothers in providing adequate information about the risk of home delivery. On other hand, family support plays a role. Usually, mothers can come for antenatal care by themselves, but not when they are in labor because they need help from others.

This could also be supported by qualitative findings. Bench Maji Zone is mostly rural and predominated by different cultural practices that might prevent women from accessing and utilizing health services. For instance, in the in-depth interview, it was reported that, laboring mothers kept in the home where people cannot see them for some days during and after delivery. In this area, childbirths are considered to be impure (could be contaminated) and laboring women would be isolated even from the family members. The present study identified that the place of last delivery is an important predictor of institutional delivery. It is consistent with studies carried out in Kenyan which identified that mothers tend to be 3.9 times more likely to deliver the last baby in the same place they delivered during the first delivery.
This shows that the first experience a mother had at the chosen place of delivery and with the chosen birth attendant was very important (19, 20). Unpleasant procedures like episiotomy and delays in hospitals or health facilities leads mothers to perceive these institutions as harsh settings that is not conducive for delivery. Similarly, those who perceived home as a risky delivery place chose to have health facility based deliveries.

In our case, previous experience of institutional delivery has negative influence on future preferences which goes exactly with the result of the in-depth interview which shows that mothers having safe home deliveries in the previous pregnancies are less likely to attend hospital unless they face severe complications.

"...I have six children, out of whom only half were born at the hospital. I had no problem related to delivery of some of my children, so I gave birth at home. But for the first and the middle baby,I faced heavy bleeding and even newborn death, which happened at hospital. I feel secured when I give birth at my home."(34 years old, model mother)."

Interviewees also mentioned issues concerning perception of women on health care providers as shouting during labor, lack of empathy, refusal to assist and lack of moral support which may influence women. Mothers may not mention these problems if they decide not to go.

This needs further exploring to identify the underlying factors related to quality of delivery service provision. This could also be supported by the fact that fear of the differences in sex and religion of HCWs which negatively affected preference of facility delivery as identified in this study. Women who mentioned that they feel shy if the care provider is male and not among their religious group were found to be less likely to prefer institutional delivery. This finding is similar with studies conducted in Nepal and Bangladesh, which revealed that moral support in making wait and giving priority on the basis of caste, ethnicity, language and religion discourage the use of institutional delivery. Mothers also worry about privacy and confidentiality $(21,22)$.

Inline with previous studies $(2,15,19)$, this study identified that the number of children women have affects the preference of delivery sites. Women who have total children greater than five were less 
likely to utilize institutional delivery according to this study. The possible reason could be due to the fact that women care for the other children and may not have time to utilize health care. Further, those with higher birth order may have had no difficulty in the previous deliveries as explained above, in the qualitative study.

Women's perception about the nature of labor was statistically associated with institutional delivery. In EDHS 2011 and previous studies, mothers who believed that sudden onset of short lasting labor that may accidentally occur combined with absence of transport facility or lack of money for transportation cost are less likely to use institutional delivery $(8,9,23)$. Lack of financial resources among rural mothers, which leaves them to the decision of their husbands or relatives, also affects facility delivery $(23,24,25)$.

Institutional delivery was not associated with ANC attendance, and previous institutional delivery had negative effects on future preferences which creates uncertainty about the quality of ANC and delivery services. This calls for further research to explore factors that affect facility deliveries from the perspectives of quality of the services and health professionals. Moreover, some traditionally customized beliefs that affect institutional delivery were recognized in the area.

Therefore, training for additional health extension workers so that they could have some delivery skills to conduct home delivery is recommended. The community should also get information, education and communication (IEC) and behavior change communication (BCC) that are directed to risks of delivery unattended by skilled personnel and traditionally customized harmful beliefs and practices.

\section{ACKNOWLEDGEMENTS}

We would like to forward our gratitude to MizanTepi University for funding the study. We also thank Bench Maji Zone Administration and Health Department, the data collectors, supervisors and the respondents for their contribution

\section{REFERENCES}

1. World Health Organization: Reconciling maternal, newborn and child health with health system development. World Health
Report 'Make every mother and child count' Geneva, Switzerland: WHO; 2005.

2. Baral YR. Determinants of skilled birth attendants for delivery in Nepal, London Metropolitan University, UK. 2010; 8(3):326329.

3. WHO, UNICEF, UNFPA, The World Bank and the United Nations Population Division: Trends in maternal mortality from 1990 to 2013.

4. Kabir M. Safe delivery practices in rural Bangladesh and its associated factors: Evidence from Bangladesh demographic and health survey-2004. East African Journal of Public Health 2007, Volume 4:67-72.

5. Ministry of Public Health and Sanitation: Annual Health Sector Statistics. 2008: available on, http://www.publichealth.go.ke.

6. United Nations: The Millennium Development Goals report: Statistical annex. New York; 2007: Accessed, http://www.un.org/millenniumgoals

7. World Health Organization. Skilled attendant at birth 2006 updates Geneva, 2006.

8. Central Statistical Agency. Ethiopia Demographic and Health Survey 2011. Addis Ababa, Ethiopia, and Calverton, Maryland, USA: Central Statistical Agency, p.126.

9. Addisalem A, Meaza D. Prevalence of institutional delivery and associated factors in Dodota Woreda (district), Oromia, Regional state, Ethiopia. BMC; Journal of Reproductive Health, 2012;33:3.

10. Alemayehu S. Institutional delivery service utilization and associated factors among mothers who gave birth in the last 12 months in Sekela District, North West of Ethiopia: BMC Pregnancy and Childbirth, 2012;74:5.

11. Hazemba AN and Siziya S. Prevalence and correlates of utilization health facilities in Chongwe district,Zambia. Medical journal of Zambia, 2008;35(2):53-57.

12. Martin P. Determinants of non-institutional deliveries in Malawi. Malawi Medical Journal; 2011;23 (4):106-108.

13. Mesfin N. Assessment of safe delivery service utilization among women of child bearing age in North Gondar, Ethio journal Health Dev; 2004; 18(3):145-151.

14. Anwer M. Inequity in maternal health-care: evidence from home-based skilled birth 
attendants programs in Bangladesh. Bulletin of the world organizations, 2008;86(4):252.

15. Asmerech M. Levels and Determinants of Use of Institutional Delivery Services among Women of Child bearing Age in Ethiopia: Analysis of EDHS 2000 and 2005 Data.

16. Tura G, Gebremariam: Safe delivery service utilization in Metekel Zone, North West Ethiopia. Ethiop journal of Health Sciences, 2011; 17(4): 231-222.

17. Nigussie M, Haile Mariam D, Mitike G: Assessment of safe delivery service utilization among Mothers of child bearing age in north Gondar Zone, North West Ethiopia. Ethiopian journal of Health Development, 2004;18(3):145-152.

18. Worku A. Jemal M. and Gedefaw A. Institutional delivery service utilization in Woldia, Ethiopia. Bahir Dar University; Science journal of public health 2013;1:18-23.

19. Wanjira C. Delivery Practices and Associated Factors among Mothers Seeking Child Welfare Services in Selected Health Facilities in South District, Kenya. BMC public health; 2011;11:4-6.

20. Cotter K, Hawken M, Temmerman H: Low Use of Skilled Attendants 'Delivery Services in Kenya. Journal of health, population and nutrition, 2006; 24(4):469-471.

21. Pradhan A. Nepal Maternal Morbidity and Mortality study 2008/2009. Family Health
Division, Ministry of Health and Population, Kathmandu, Nepal. International journal of obstetric and gynecology: 2010;26-30:118.

22. Iftekher $\mathrm{H}$. and Mohammad M. Determinants of choices of Delivery care in some urban slums of Dhaka city. University of Bangladesh. Pakistan Journal of Social Sciences, 2005;3(3):469-475.

23. Fantahun M. Factors affecting ANC attendants and preference of delivery by pregnancy women in Gulale Woreda. Ethio journal Health Dev.1992, v6(2):17-22.

24. Mrisho M. Factors affecting home delivery in rural Tanzania. Trop Med Int Health, 2007; 4(2): $62-72$.

25. Hounton S, Chapman G, Ronsmans C: Accessibility and utilization ofdelivery care within a skilled care initiative in rural Burkina Faso. Trop Med Int Health, 2008; 6(3):44-52.

26. MOH, Macro USA: USAID, UNICEF, DFID. Kenya Service Provider and Assessment Survey: KSPAS Maternal and Child health, Family planning and Sexually Transmitted Infections National Coordination Agency for population and Development, 2006.

27. Daniel Bogale Odo, Desalegn Markos Shifti. Institutional Delivery Service Utilization and Associated Factors among Child Bearing Age Women in Goba Woreda, Ethiopia, Journal of Gynecology and Obstetrics, 2014;2(4):63-70. 